\title{
Dutch type periodic fever in a Turkish infant also having MEFV mutation
}

\author{
B Makay, F Demirciooglu, M Duman and E Ünsal*
}

Address: Dokuz Eylul University Hospital, Izmir, Turkey

* Corresponding author

\author{
from 15th Paediatric Rheumatology European Society (PreS) Congress \\ London, UK. 14-17 September 2008 \\ Published: 15 September 2008 \\ Pediatric Rheumatology 2008, 6(Suppl I):P20I doi:I0.I I86/I546-0096-6-SI-P20 I
}

This abstract is available from: http://www.ped-rheum.com/content/6/SI/P20I

(C) 2008 Makay et al; licensee BioMed Central Ltd.

\section{Background}

Dutch type periodic fever (DPF) is a hereditary fever syndrome caused by a deficiency of the enzyme mevalonate kinase (MVK). The most of the patients have been reported from France and Netherlands.

\section{Case report}

A seven-month-old Turkish boy was consulted to Pediatric Rheumatologist for evaluation of periodic fever. He experienced fever episodes since two months following birth once or twice a month, lasting for 2-4 days. He had been hospitalized for 4 times to identify the etiology of fever. Conjunctivitis without periorbital edema and diarrhea accompanied almost every attack. In one of these attacks, he had a unilateral cervical lymphadenopathy. He had erythematous macules at one fever episode. In every attack CRP was extremely elevated. His uncle had chronic renal insufficiency of unknown etiology. FMF was suspected. The heterozygous V726A variant of MEFV was detected. He was put on colchicine; however he did not respond despite 6 months of therapy. His serum IgD levels were normal during attacks. Association of lymphadenopathy and diarrhea with recurrent fevers considered DPF. Genetic analysis revealed two mutations on MVK gene. He was put on simvastatin $5 \mathrm{mg} /$ day. The 4 months course of simvastatin therapy failed to reduce the attacks.

\section{Conclusion}

This is the third case of DPF reported from Turkey. The presented case shows a rare coincidence of MVK gene with MEFV mutation. The first case also had a heterozygous MEFV mutation and did not respond to simvastatin [1].
The presence of MEFV mutation in DPF might be a poor prognostic sign regarding the response to therapy.

\section{References}

I. Demirkaya E, Çağlar MK, Waterham HR, Topaloğlu R, Ozen S: A patient with hyper-IgD syndrome responding to anti-TNF treatment. Clin Rheumatol 2007, 26:1757-9. 